\section{SEISMOLOGY IN JAPAN.}

U NDER the title of " Recent Seismological Investigations in Japan," Baron Dairoku Kikuchi, former Minister of Education, has issued for private circulation only an "address "prepared for the late ex-

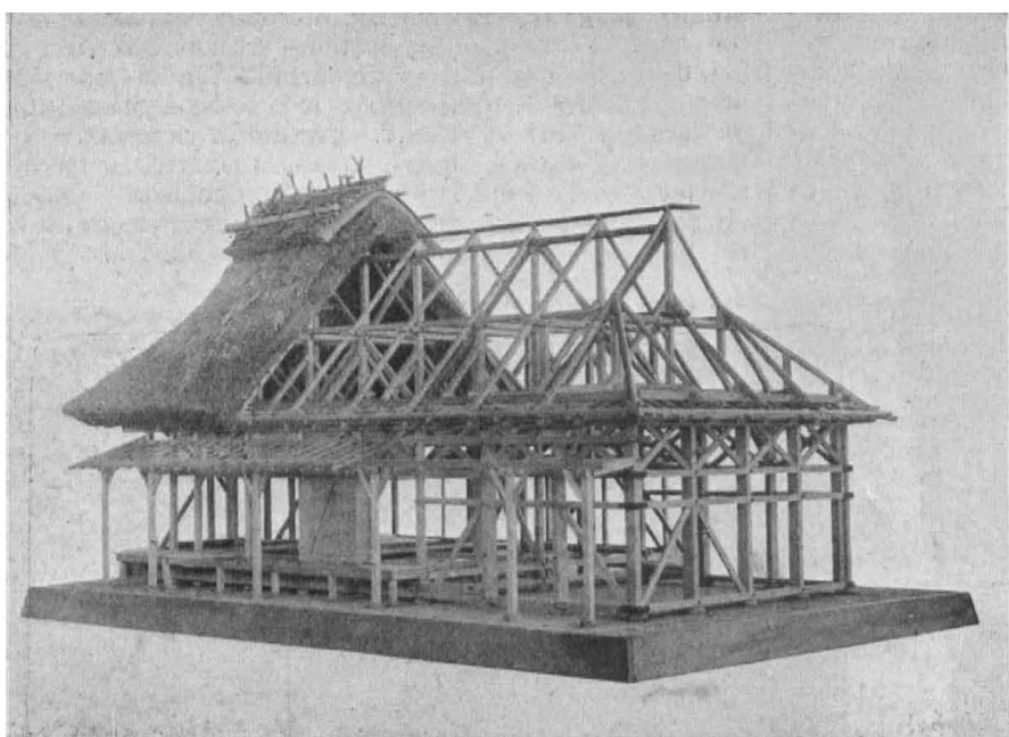

Fig. x.-Model of a Farmer's Cottage. Showing the essential points of construction recommended by the Earthquake Investigation Committee. The chief points to be observed are diagonal bracing, the use of iron straps, and the avoidance of mortices and other cuts at joints. and various phenomena. Earthquakes which have a submarine origin are most frequent in summer, when the level of the Pacific Ocean bordering Japan is higher than in winter. Those originating on the land are most frequent in winter, at which season barometric pressure is at a maximum. Out of forty-seven destructive earthquakes which originated beneath the Pacific, twenty-three were accompanied by tsunami or sea waves, which probably means that on these occasions marked and sudden changes had taken place in the configuration of the sea bed.

Among the instruments which are described we notice a horizontal pendulum the bob of which is controlled by a small inverted pendulum. Although the vertical and horizontal dimensions of this apparatus are each only I metre, Prof. Omori tells us that a period of one minute can be obtained without difficulty. Macroseismic motion is described, and after this reference is made to microseisms or pulsations. These two classes of movement Prof. Omori finds alternate in their frequency, so that when the small movements are at a minimum the larger ones may be expected. This observation, we learn, has enabled him on several occasions to predict within ten or twelve hours the occurrence of an earthquake.

position in St. Louis. When we look at this address, which is a quarto volume of ${ }_{3} 6$ pages filled with illustrations, we feel that its author should have doffed his modesty and called it seismology as developed in Japan. To describe the work more closely, we shall not be far from the mark if we say it is an epitomised translation of a number of publications which to Europeans have hitherto been cryptogramic. It gives us not only a résumé of sixteen numbers of the publications of the Tokyo Earthquake Investigation Committeecalled for short the E. I. C.which have been published in a European language, and with which we are more or less familiar, but there is added an abstract of forty-seven numbers or volumes published in Chinese idiographs. Many seismologists have looked at them and wondered what they meant. The contents of these sixty-three publications have been epitomised, mixed, and systematised.

After an introduction to the "recent" investigations, which tell us that the first earthquake recorded in Japan was in A.D. 416 , and reference to various investigations made by Europeans in Japan, we are introduced to the system under which investigations and their results have been classified and discussed.

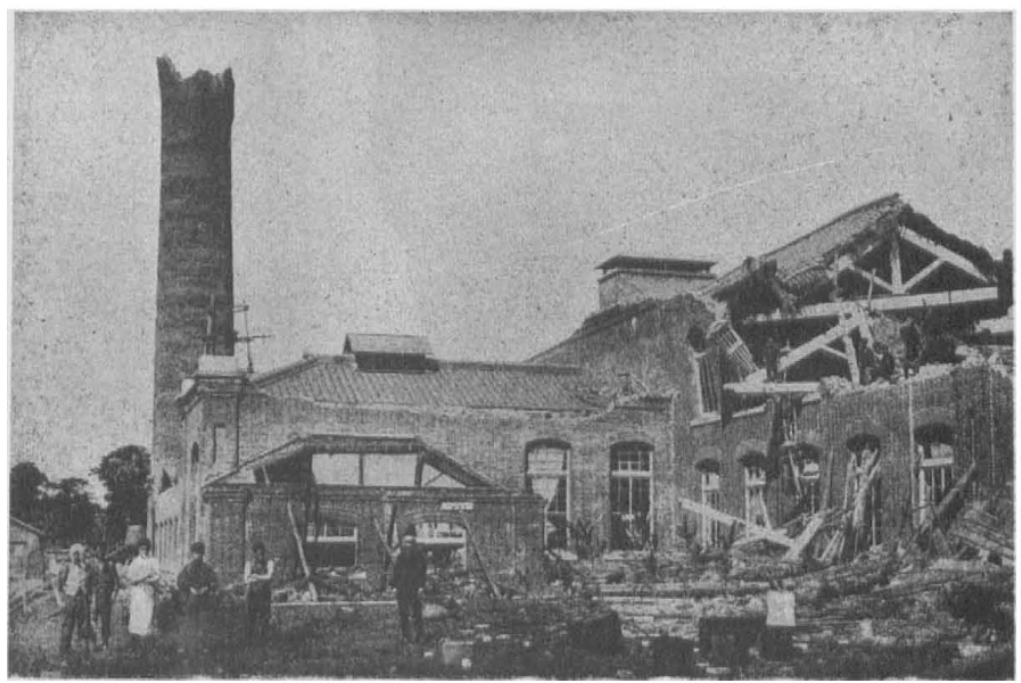

The geological investigations which have been made chiefly refer to the survey of volcanoes, which is a work outside that done by the Geological Survey.

The investigations of relationships that may exist between earthquakes and various physical phenomena

Under the heading "Statistical" we find data relating to the distribution of earthquakes in space and time, their relation to meteorological conditions,

$$
\text { NO. } 1836 \text {, vOL } 717
$$
crust are particularly interesting. At present continuous magnetic observations are being made in Japan has been observed that on several occasions magnetic which affect or are affected by strain in the earth's at five stations, from which, amongst other things, it 
needles have been disturbed before or at the time of large earthquakes. Speaking generally about these investigations, Baron Kikuchi considers that they promise to throw light upon the state of underground stress, and as one of the chief objects of the E. I. C. is to devise means to predict earthquakes which may be taken as announcements that stress has been relieved, it will be recognised that the inquiries relating to local magnetic disturbance are of a promising nature.

Other phenomena which receive attention are variations in latitude, the determination of gravity, underground temperatures, seiches, changes in the level of water in wells, and the elastic constants of rocks.

The last section of this interesting volume is an account of investigations which have been made with the object of reducing the disastrous effects of earthquakes to a minimum. To the practical person this is no doubt the most important branch of all seismological research. Already it has accomplished much, and after a severe shaking we have learned that in Japan new types of structures are to be seen standing amongst the ruins of older types.

We welcome Baron Kilsuchi's volume, and trust that although its circulation is private it may also be wide.

THE FOUNDER OF AUSTRALIAN ANTHROPOLOGY.

DR. A. W. HOWITT is our highest authority on the native tribes of Australia. Ever since the publication of "Kamilaroi and Kurnai," in I880, he has been adding to our knowledge of the most instructive and interesting aboriginal population in the world The present work, therefore, which summarises the data collected by him during forty years of personal intercourse with the "blackfellows," is of the greatest importance. Most of the material here incorporated was written up before 1889 ; a few modifications of theory and many new facts have been introduced, and some corrections made, but the broad deductions remain unaltered.

The main body of the work is preceded by a useful summary and criticism of the principal views that have been put forward as to the origin and ethnological affinities of the Tasmanian-Australian stock; Dr. Howitt rejects both the Dravidian and the Malayan hypotheses. The tribes here dealt with came into contact with the white man at a date too early, perhaps, to allow them much chance of survival; many of them are now practically extinct, and most of them are at least deorganised. The area they occupied is about one-quarter of the contınent, extending on the north to near the tropic of Capricorn, and on the south bordered by the Southern and Pacific Oceans, connected by Bass Strait. This area has a wide range of climate and temperature, and the tribes themselves present almost every variety of social organisation, from that of the Dieri and central districts through the ordinary Australian types to the unique system of the Kurnai in Gippsland. Excellent

1 "The Native 'Tribes of South-East Australia." By A. W. Howitt, D. Sc. Pp. xix +8 ro; illustrations and maps. (London: Macnillan and Co., Ito, 1904) Price $21 s$.

NO. I 836 , voI. 7 I ] maps, very numerous and complete, illustrate both the tribal areas and the range of the various social systems.

In this matter of organisation Dr. Howitt traces the gradations in a way conclusive enough to point to the probable course of evolution. In particular he reduces the problem of exogamy to the bisection of the community into two exogamous intermarrying moietiesthe typical Australian system-which bisection is based, as he implies, on the prohibition of marriage between brothers and sisters. It is to be regretted that he does not fully discuss this ground of exogamy. $\mathrm{He}$ quotes Dr. Frazer and the present writer as having independently reached the same conclusion, and it seems that we are at last approaching unanimity as to this primal law of human social relations. He

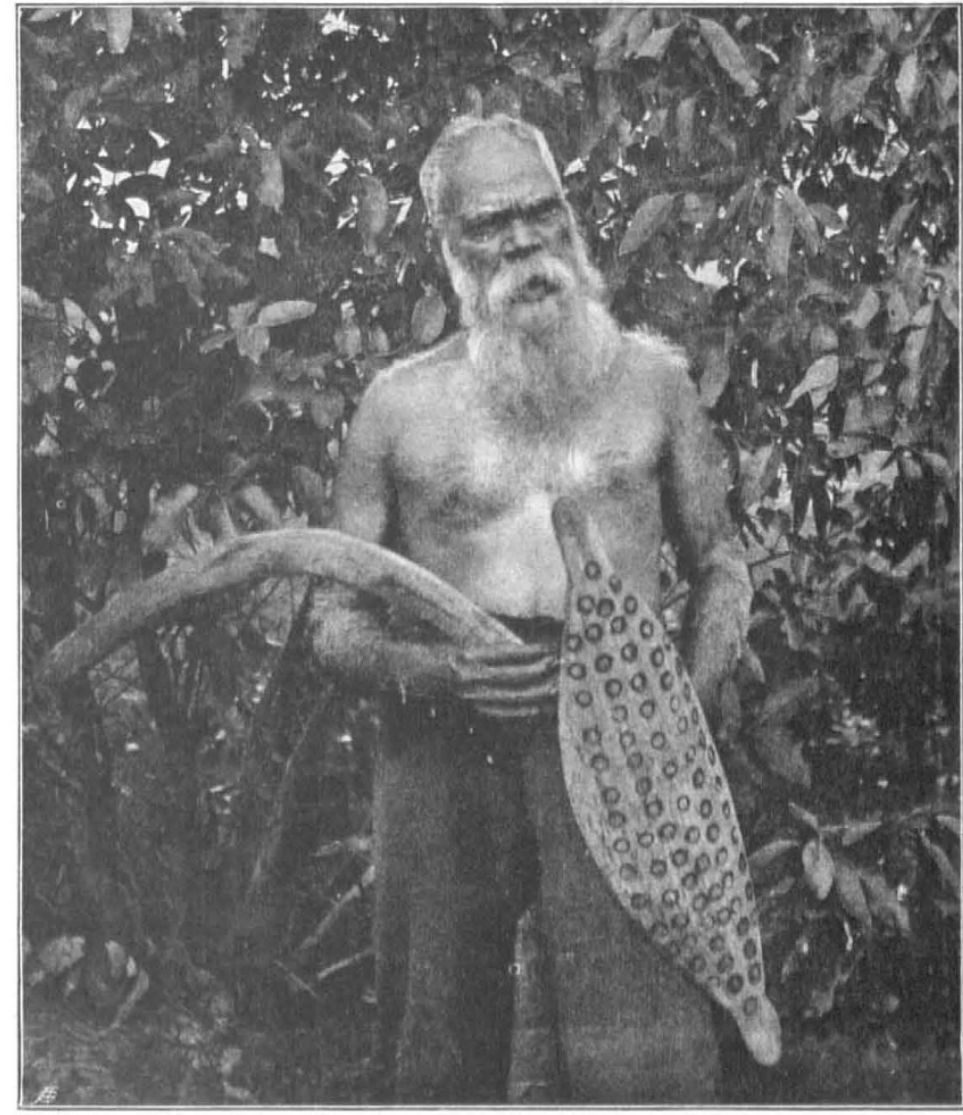

ung Clan of the Kurnai Tribe. From Howitt's "The Native Tribes of South.East Australia." agrees with Spencer and Gillen that the primary functions of totemism were in existence before exogamy became established, and that the relation between totemism and exogamy is secondary only. On the other hand he sees no reason to modify his original view that the bisection was a reformatory measure, instituted after a long reign of the "Undivided Commune." It is doubtless impossible to deny some purposiveness to the innovation, if innovation it was; Mr. Lang is here inclined to agree. But to engineer such bisection in a large undivided commune seems beyond the powers even of primitive man. A shorter way may be easily suggested :- the moieties practically correspond to two groups of intermarrying relatives; we may suppose, then, to begin with, two small families or fire circles, $\mathrm{A}$ and $\mathrm{B}$, making inter- 